\title{
Are women a different group of HIV-infected individuals?
}

\author{
Adriana Carvalhal
}

Published online: 4 May 2010

(C) Springer-Verlag 2010

The HIV infectious has become one of the most serious epidemics worldwide, with significant impact on mortality, morbidity, overall quality of life, and the use of health care services. The HIV epidemic remains unstable and the latest statistics of the global HIV and AIDS were published by UNAIDS in November 2009, and refer to the end of 2008. It is estimated that 33.4 million people are living with HIV/ AIDS and the epidemic has been changing. The most notable change observed is the increase in the proportion of women infected. The proportion of women diagnosed with HIV has dramatically increased in recent years and accounted for $50 \%$ of all adults living with HIV worldwide (www.unaids.org/en/ KnowledgeCentre/HIVData/EpiUpdate/EpiUpdArchive). While mortality from AIDS has been largely controlled through the availability of antiretroviral therapy (ART), several physical and psychosocial complications remain serious concerns. A diagnosis of HIV can carry with it tremendous social stigma. Women living with HIV face not only a chronic illness and complex medical demands but also extensive social challenges, including access to health care, financial assistance, emotional and social support, assistance with daily activities, housing, and family services (Bing et al. 2001). Many people with HIV struggle with social and economic stresses that have a negative effect on their health. In a survey conducted for the Canadian AIDS Society, almost $60 \%$ of people with HIV reported annual incomes of less than $\$ 20,000$ (De Bruyn 1998). According to the

\footnotetext{
A. Carvalhal $(\triangle)$

Department of Psychiatry \& Behavioural Neuroscience,

McMaster University,

4th Floor, Fountbonne Building F414, 50 Charlton Avenue East, Hamilton, ON, Canada L8N 4A6

e-mail: carvalh@mcmaster.ca
}

Ontario HIV/AIDS Strategy (Network CAA 2004), as well as the Federal Initiative to Address HIV/AIDS in Canada, poverty, lack of affordable housing, homelessness, racism, stigma, and discrimination all contribute to HIV infection, disease progression, and a person's ability to manage and live with the disease (PHAo 2002). Gender inequities also drive the epidemic. A survey of 110 women infected with HIV found that $53 \%$ of women had been sexually assaulted as an adult, $43 \%$ had been sexually abused as a child, and $27 \%$ had been sexually abused or assaulted as both a child and as an adult. Women who were abused were almost seven times more likely than those who were not to engage in injection drug use (Network CAA 2004). Abused women are four times more likely than others to engage in high-risk sex (Kirkham and Lobb 1998). The biggest barrier that women face in disclosing their HIV status to their partners is fear of violence. Risk factors for experiencing abuse after disclosure of HIV status include prior history of abuse, drug use, and having a low income (El-Bassel 1998).

Research has shown that a person's ability to cope with HIV infection can be influenced by a multitude of psychosocial variables, including depression and quality of life (Ciesla and Roberts 2001; Grassi et al. 1998; Sherbourne et al. 2000). Depression is a common co-morbidity in patients with HIV infection. Estimates of the prevalence of major depressive disorders in people living with HIV/AIDS (PHAs) vary widely in the literature, with reported prevalence rates that range from $1.9 \%$ to $35 \%$ in clinical samples and from $30 \%$ to $60 \%$ in community samples (Bing et al. 2001). Depression is associated with poor health, greater health service utilization, and adverse affects on quality of life and social support. Depressive symptoms are associated with poor adherence to HIV medication (Wagner et al. 2010), HIV disease progression (Miller et al. 2006), poor social support, and poor quality of 
life. Psychological stress plays an important role in the development of depressive symptoms (St. Lawrence et al. 2008). Several factors have been identified that may predict increased depression in PHAs. These include: number of years living with an HIV-positive diagnosis, avoidant versus active coping style, excessive rumination about healthrelated problems, past history of depression, personality disorders, and low levels of social support (Ciesla and Roberts 2001). In this special issue, Mello et al. shows that HIV-positive women have high prevalence of lifetime and current depression and it might be due to a combination of fear of death, stigma and discrimination, having to act as caregivers and experiencing adverse effects from ARV. Depressed women had higher viral load than non-depressed ones and there were association between depression and lack of emotional support (Mello et al. 2010).

HIV/AIDS manifests itself differently in women than men; women take on social and work roles that are distinct from men and quality of life for HIV-positive women has been severely understudied despite its significant relationship with social support. The diversity of and vulnerability to stressful events that HIV-positive women are likely to encounter are inherently different than that faced by HIVpositive men or HIV negative women (Shannon et al. 2008). Ndlovu et al. describes that child-related stressors are the most challenging stressors faced by HIV-positive women and seeking social support was an important component of coping response for the participants in that study (Ndlovu et al. 2010). Greene et al. highlight the complex and unique needs of HIV-positive parents who live with and care for their children and the central role that housing plays in their lives. HIV-positive parents experienced a number of interconnected barriers to living in appropriated and stable housing. Poor housing conditions, unsafe neighborhoods, barriers to social support, HIV related stigma, discrimination, racism, and poverty have been identified by these families. This results in increased stress and anxiety that has a negative impact on mental health of HIV-positive parents (Greene et al. 2010).

Due to the shift in perspective, HIV-positive women have new opportunities such as the possibility of motherhood. HIV-positive women are increasingly becoming pregnant and giving birth. Recent studies indicate that the rates of pregnancy amongst HIV-positive women may further increase over time as a result of the success of combination antiretroviral therapy with undetectable viral loads, vertical transmission rates being less than $1 \%$, and a normalization of pregnancy for HIV-positive women (Shannon et al. 2008). Moreover, women who are at risk for HIV are also at risk for unplanned pregnancies (Miller et al. 2006; St. Lawrence et al. 2008) which may also increase rates of pregnancy amongst HIV-positive women. Hence, having children is a growing reality for women living with
HIV highlighting the need for increased research exploring their diverse experiences of pregnancy and early motherhood. Wagner et al. describes now negative experience with physicians around reproductive health care is associated with higher perceived stigma. The importance of health care provider support and acceptance regarding HIVpositive women's fertility decision is reflected in their overall perceived HIV stigma.

This special topic in Archives of Women's Mental Health discusses important aspects of HIV-infected women. HIV/ AIDS manifests itself differently in women than men; women take on social and work roles that are distinct from men and this group of individuals has been severely understudied despite its represents $50 \%$ of all adults infected by HIV.

\section{References}

Bing E, Burnham M, Longshore D, Fleishman JA, Sherbourne CD, Turner LAS, BJ EF, Beckman R, Vitiello B, Morton SC, Orlando M, Bozzette SA, Ortiz-Barron L, Shapiro M (2001) Psychiatric disorders and drug use among human immunodeficiency virusinfected adults in the United States. Arch Gen Psychiatry 58 (8):721-728

Canada PHAo (2002) HIV/AIDS and Health Determinants: Lessons for Coordinating Policy and Action. A Discussion Paper for the Ministerial Council on HIV/AIDS, http://phac-aspc.gc.ca/aids-sida/ hiv_aids

Ciesla J, Roberts J (2001) Meta-analysis of the relationship between HIV infection and risk for depressive disorders. Am J Psychiatry 158:725-730

De Bruyn T (1998) Force for change: labour force participation for people living with HIV/AIDS. In: Society CA

El-Bassel N (1998) Partner violence and sexual HIV-risk behaviors among women in an inner city emergency department. Violence Vict 13:377-393

Grassi L, Righi R, Sighinolfi L, Makoui S, Ghinelli F (1998) Coping styles and psychosocial-related variables in HIV-infected patients. Psychosomatics 39:350-359

Greene S, Tucker R, Rourke SB, Guenter D, Ahluwalia A, Monette L, Koornstra J, Sobota S, Byers S, Hwang S, Dunn J, Guenter D, Ahluwalia A, Watson J (2010) "Under my umbrella": the housing experiences of HIV positive parents who live with and care for their children in Ontario. Arch Womens Ment Health. doi:10.1007/s00737-009-0090-5

Kirkham C, Lobb D (1998) The British Columbia positive women's survey: a detailed profile of 110 HIV-infected women. Can Med Assoc 158:317-323

Mello VA, Segurado AA, Malbergier A (2010) Depression in women living with HIV: clinical and psychosocial correlates. Archives Women's Mental Health. doi:10.1007/s00737-0090094-1

Miller RL, Pallant JF, Negri LM (2006) Anxiety and stress in the postpartum: is there more to postnatal distress than depression. BMC Psychiatry 6(1):12-12

Network CAA (2004) HIV/AIDS and aboriginal women, children and families. In: www.caan.ca

Ndlovu U, Ion A, Carvalhal A (2010) "My children and my home": the most recent and challenging stressors of HIV-positive 
women. Archives Women's Mental Health. doi:10.1007/s00737010-0148-4

Shannon K, Kerr T, Allinott S, Chettiar J, Shoveller J, Tyndall MW (2008) Social and structural violence and power relations in mitigating HIV risk of drug- using women in survival sex work. Soc Sci Med 66(4):911-921

Sherbourne C, Hays R, Fleishman J, Vitiello B, Magruder KM, Bing EG, McCaffrey D, Burnam A, Longshore D, Eggan F, Bozzette SA, Shapiro MF (2000) Impact of psychiatric conditions on health-related quality of life in persons with HIV infection. Am J Psychiatry 157:248-254

St. Lawrence JS, Snodgrass CE, Robertson A, Baird-Thomas C (2008) Minimizing the risk of pregnancy, sexually transmitted diseases, and HIV among incarcerated adolescent girls: identifying potential points of intervention. Crim Justice Behav 35(12):1500-1500

Wagner AC, Hart TA, Mohammed S, Ivanova E, Wong J, Loutfy M (2010) Correlates of HIV stigma in HIV-positive women. Archives Women's Mental Health. doi:10.1007/s00737-010-0158-2 